\title{
Effects of Water and 50\% Ethylene-Glycol Coolant Characteristics on Nucleate Boiling Heat Transfer in IC Engine Cooling System
}

\author{
Haoyu Chen ${ }^{1)}$ (akashi Suzuki ${ }^{2)}$ Koki Asano ${ }^{1)}$ Ryota Shindo ${ }^{1)}$ Ayumi Homma ${ }^{1)}$ Naoya Kimata ${ }^{1)}$ \\ Takaki Nakaya ${ }^{1)}$ Kakeru Nakamura ${ }^{1)}$ Emir Yilmaz ${ }^{2)}$ Mitsuhisa Ichiyanagi ${ }^{2)}$ \\ 1) Sophia University, Graduate School of Science and Technology \\ 7-1 Kioi-cho, Chiyoda-ku, Tokyo, 102-8554, Japan \\ 2) Sophia University, Department of Engineering and Applied Sciences \\ 7-1 Kioi-cho, Chiyoda-ku, Tokyo, 102-8554, Japan
}

Received on June, 10, 2021

\begin{abstract}
To improve the cooling system of internal combustion engines, the utilization of the nucleate boiling heat transfer is desired. Our previous study revealed the relationship between the water nucleate boiling heat flux and dimensionless numbers. By using $50 \%$ ethylene glycol aqueous solution (EG50\%) as coolant, the nucleate boiling heat flux was measured on the corroded heating surface and compared with the experimental data of water as coolant. Subsequently, dimensional analyses were done to investigate the necessary dimensionless numbers affecting the forced flow nucleate boiling. Two new models are proposed for water and EG50\% as coolants, and predicted heat flux results were found to be in an average error of $9.7 \%$ and $10.1 \%$, respectively.
\end{abstract}

KEY WORDS: heat fluid, refrigerant, engine cooling, thermal management, forced flow nucleate boiling, heat transfer (D1)

\section{Introduction}

Recently, greenhouse gas emission regulations and fuel economic performance of internal combustion engines (ICEs) are becoming more stringent, thus sophisticated thermal management developments for ICEs are required. In order to achieve higher thermal efficienies and miniaturization of heat exchangers, nucleate boiling phenomenon with higher heat flux at high coolant temperature can be utilized. It is considered to be feasible to realize high temperature coolant operation and ensure higher cooling efficiencies by keeping the heat flux at nucleate boiling phase inside the coolant path through the control parameters, such as coolant flow rate, temperature, system pressure, and so forth.

In the previous studies, Chen ${ }^{(1)}$ proposed that the forced flow nucleate boiling heat transfer coefficient is the superposition of heat transfer coefficient of forced convection and pool nucleate boiling, and suggested the restricting factors of these two kind of heat transfer coefficients at saturated boiling flow. Steiner et al. ${ }^{(2)}$ followed this superposition approach based on Chen's model and focused on the application of nucleate boiling phenomenon using water/ethylene-glycol mixtures as coolant fluid for ICEs. Unlike Chen's model, Steiner et al. (2) reconstructed the inhibition factor by using bubble dynamics based on Forster \& Zuber's model (3). This model was based on dimensionless numbers created by coolant fluid's physical quantities at vapor and liquid phases, and is also considered as the base model in this study to analyse pool nucleate boiling. In another study, carried out by Torregrosa et al. (4), low flow operation experiments were carried out using the engine. By comparing the experimental data with Chen's model, the results showed that Prandtl number has a significant effect on the restricting factor proposed by Chen.
Although Chen's model is referenced extensively and have been proven that it can accurately predict the nucleate boiling heat flux in simple coolant operation conditions, its accuracy found to be decreased when used in the coolant systems of ICEs. This issue is also mentioned in Steiner et al. ${ }^{(2)}$, where the bubble dynamics were re-analysed in vapor and saturated temperature conditions of the coolant fluid, to overcome the decreased accuracy. However, when the coolant fluids are changed, prediction results from the previous models are found to be different from the experimental results. Car manufacturers have been using not only Long-Life Coolant (LLC) but also water and ethylene glycol aqueous solution as coolant fluid to verify the heat transfer performances of various engine parts ${ }^{(5-7)}$. The above fluids, except LLC, tend to be corrosive in hot and hostile conditions after a short period of time. The spatial corrosion in the cooling channels is observed as an important factor affecting the nucleate boiling due to altered surface properties, which are rarely presented in the literature.

There are two main objectives of this study. One is to measure the forced flow nucleate boiling heat fluxes by using water and $50 \%$ ethylene glycol aqueous solution (EG50\%) as coolant fluids, which are the primary components of LLC for automobiles without any anti-rust properties. The other is to improve the prediction accuracy of the forced flow nucleate boiling heat transfer model. In our previous study ${ }^{(8)}$, an experimental apparatus was constructed with a horizontal heating surface and channel which can simulate the coolant fluid flow conditions similar to ICEs. After confirming the spatial corrosion areas on the heated surface, surface roughness properties with and without corrosion were measured. Consequently, the measurement results of nucleate boiling heat flux were compared, and the effect of corrosion on the heating surface microgeometry and the nucleate boiling heat flux were 
Vol.12, No.3(2021)

discussed. By comparing with the experimental results used water as the coolant, the difference of EG50\% boiling and heat transfer phenomena were analyzed. Moreover, the dimension analysis was carried out by using the factors related to the forced flow nucleate boiling phenomenon, and the heat flux prediction model for corroded surface was constructed using dimensionless numbers including Jakob number, Capillary number, Prandtl number, based on the experimental results of water and EG50\%.

\section{Experimental Setup and Method}

\subsection{Experimental apparatus}

\subsubsection{Experimental pipeline}

The experimental apparatus used in this study is consistent with our previous study ${ }^{\left({ }^{8}\right)}$. The experimental coolant channel schematic diagram is shown in Figure 1. As an improvement, a swirl pot was added after the electric pump outlet to remove the tiny bubbles remained in the pipeline. Furthermore, to achieve a wider flow control range, a pipeline with a smaller measurable flow range flowmeter was set downstream of the plug heater. Thermocouples and pressure sensors were set at the inlet and outlet of the observation section to measure the bulk temperature and the pressure of the heat flux measurement position.

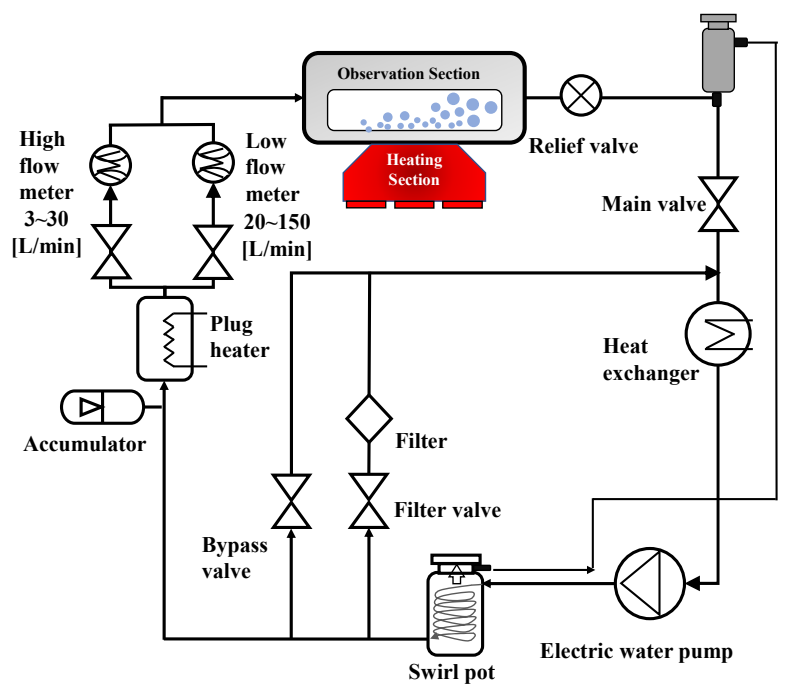

Fig. 1 Schematic of experimental apparatus of the heated closed-loop cooling system with observation area

\subsubsection{Observation and measurement section}

The schematic diagrams of the observation and the heating sections that were used in this study are shown in Figure 2. The observation section is designed as a $30 \mathrm{~mm} \times 30 \mathrm{~mm}$ rectangular channel and placed horizontally. Two glass observation windows and a polycarbonate LED light window, $20 \mathrm{~mm} \times 60 \mathrm{~mm}$, are set on the front, back and top sides of the observation section channel. The growth and movement of bubbles can be observed by a high-speed camera set in the horizontal and vertical directions. In addition, a heating block made of aluminum alloy (A2017) is inserted into the bottom of the observation section. $6 \times 555 \mathrm{~W}$ ceramic heaters are installed with 9 thermocouples at the bottom of the heating block, shown in Figure 2 (b). The temperature distribution is assumed to be linear and the heat fluxes are calculated by Fourier's law.

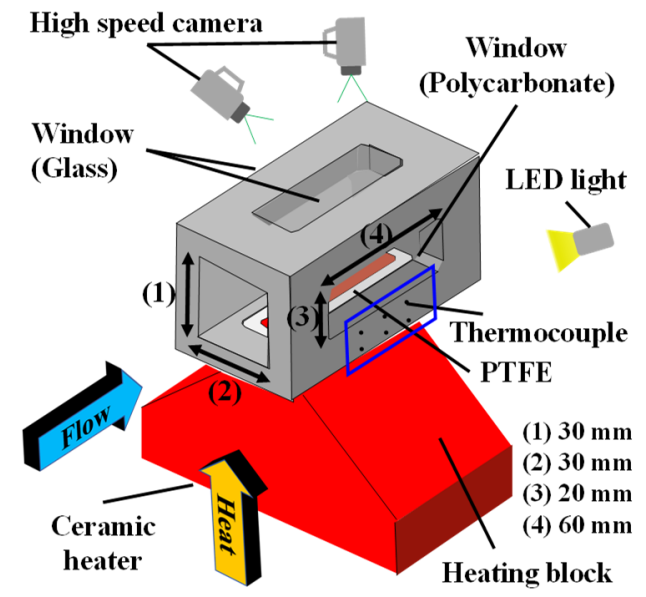

(a)

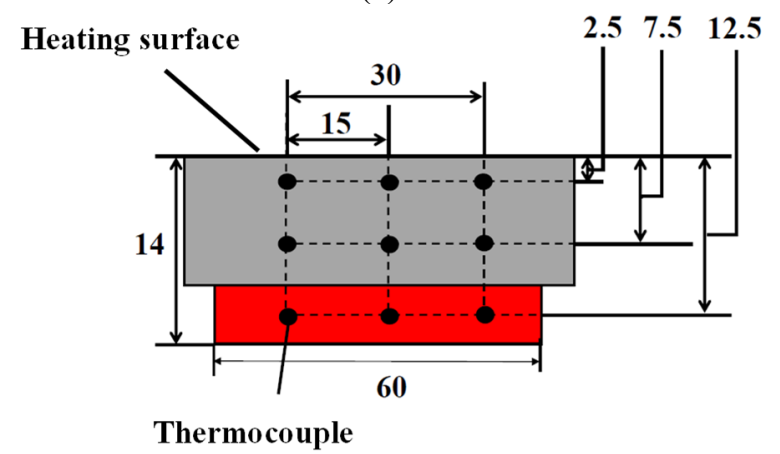

(b)

Fig. 2 Schematic of rectangle channel with heating section (a) and thermocouples locations (b).

\subsection{Experimental conditions}

In this paper, experimental conditions that simulated engine operating were carried out and are shown in Table 1 . In a rectangular channel with a size of $30 \times 30 \mathrm{~mm}$, water and EG50\% are used as working fluids, and the heating surface with a surface roughness of $R a=3 \mu \mathrm{m}$ made of aluminum alloy is used to conduct nucleate boiling heat flux measurement experiments. In the experiment with water, the operating conditions were set as; the pressure of $0.11 \mathrm{MPa}$, the flow velocity range to $0.56 \mathrm{~m} / \mathrm{s}-0.99 \mathrm{~m} / \mathrm{s}$, and the degree of subcooling range of $9 \mathrm{~K}$ and $24 \mathrm{~K}$. For EG50\% case, the operating conditions were set as; the pressure range of $0.11 \mathrm{MPa}-0.21 \mathrm{MPa}$, the flow velocity range of $0.56 \mathrm{~m} / \mathrm{s}-0.99$ $\mathrm{m} / \mathrm{s}$, and the degree of subcooling range of $20 \mathrm{~K}$ and $41 \mathrm{~K}$.

Table 1 Experimental conditions

\begin{tabular}{|c|c|}
\hline Channel width $[\mathrm{mm}]$ & 30 \\
\hline Channel height $[\mathrm{mm}]$ & 30 \\
\hline Coolant component & Water, EG50\% \\
\hline Surface roughness, $R_{a}[\mu \mathrm{m}]$ & 3 \\
\hline Heating surface material & $\begin{array}{c}\text { Aluminum alloy } \\
\text { (A2017) }\end{array}$ \\
\hline Observation section pressure $[\mathrm{MPa}]$ & $0.11,0.16,0.21$ \\
\hline Observation section flow velocity $[\mathrm{m} / \mathrm{s}]$ & $0.56,0.70,0.85,0.99$ \\
\hline $\begin{array}{c}\text { Degree of subcooling of } \\
\text { water }[\mathrm{K}]\end{array}$ & 24,9 \\
\hline Degree of subcooling of EG50\%[K] & $41,31,25,20$ \\
\hline Degree of superheating $[\mathrm{K}]$ & $-22-52$ \\
\hline
\end{tabular}


Vol.12, No.3(2021)

\section{Results and Discussion}

3.1. Effect of corrosion on heating surface microgeometry and heat flux

To simulate the influence of the deterioration of the LLC's rust prevention effect on the forced flow nucleate boiling heat flux, EG50\% was used as degraded LLC. In Figures 3 (a) and (b), image of the heating surface before the heating experiment and after 70 hours heating experiment are shown. After 70 hours of heating, it is confirmed that most the area of heating surface was covered by black oxide. This black oxide phenomenon was analyzed by using an X-ray micro-analyzer in the study of Boehmite films by Yamada and Okamoto ${ }^{(9)}$. It was found that the impurities containing Silicon and Calcium ions in the liquid were attached to the Boehmite films, formed by the reaction of the liquid with high temperature water. In order to investigate the effect of the corrosion on the heating surface, the surface microgeometry and surface roughness of the heating surface before and after corrosion were measured by a laser microscope (Olympus OLS4000). The $3 \mathrm{~mm} \times 3 \mathrm{~mm}$ measurement areas I and II are shown in Figure 3 (b). Area I is covered by black oxide, and Area II is not covered by black oxide (later referred as white area). The measured results of the surface roughness of the heating surface before the experiment were used as a base, and the results are shown in Figure 4 (a), the roughness curves of the black area and white area are shown in Figures 4 (b) and (c), and the results of $S_{a}, R_{l o}$ and $S_{s k}$ obtained by laser microscope are shown in Table 2. Here, $S_{a}$ is arithmetical mean height, $R_{l o}$ is the developed length of the roughness profile expressed in $\%$ of expansion above $100 \%$ from the smooth profile, and $S_{s k}$ is the degree of bias of the roughness shape. Through the comparison between Figures 4 (a) and (b), the high frequency fluctuation of the roughness curve at area $I$ is reduced when compared to that before the experiment. It can be considered that the number of tiny cavities on the heating surface is reduced, and this is also reflected in $R_{l o}$ as the area I resulted as $1.9 \%$, which decreased by $79.1 \%$, compared to $9.1 \%$ before the experiment. Furthermore, the surface arithmetic mean height $S_{a}$ also decreased from $3 \mu \mathrm{m}$ to $2.3 \mu \mathrm{m}$. This concludes that the heating surface is covered with black oxide, resulting in a decrease in the number and depth of cavities that exist on the surface. However, the $S_{s k}$ in the black area is close to 0 before and after surface corrosion, so the black oxide does not affect the height distribution of the heating surface. On the other hand, a pit with a depth of $159 \mu \mathrm{m}$ was observed in the white area, as shown in Figure 4 (c), and similar material loss phenomenon was also found in other white areas. It can be considered that because the $\mathrm{Al}_{2} \mathrm{O}_{3}$ oxide film is destroyed and regenerating is inhibited by the doped $\mathrm{Cl}^{-}$ion in the coolant, the anodic electrochemical reaction, and corrosion is promoted. Due to the formation of corrosion pits, the measurement results of $R_{l o}$ and $S_{a}$ in this area are greater than the measurement results of the heating surface before the experiment, and $S_{s k}$ of -2.64 means the height distribution is lower.

To investigate the effect of corrosion on nucleate boiling heat transfer, the heat flux measurement experiments were carried out before and after heating surface corroded under the condition of the degree of subcooling of $41 \mathrm{~K}$, pressure at $0.16 \mathrm{MPa}$, and flow rate of $0.99 \mathrm{~m} / \mathrm{s}$. The measured surface heat flux and the nucleation site density (NSD) results are based on self-made program analysis is compared, and the results are shown in Figure 5. The data measured without boiling at low overheating is indicated by marks of $\times$. According to the results, it was confirmed that NSD results and the heat flux have a large decrease after the heating surface was covered with black oxide after 70 hours. The result of the decreased of nucleate boiling heat flux with the long-operation time was also obtained by Steiner et al. ${ }^{(10)}$. According to the measurement results of surface microgeometry, it can be speculated that the number of cavities on the heating surface covered with black oxide is reduced, which makes it more difficult to form bubble, and results in decreased the heat flux at the same degree of superheating. Furthermore, results taken by a high-speed camera in the vertical direction before and after corrosion are analyzed. The analyzed section III is shown in Figure 3 (b) which contains both black and white areas. The local NSD in the white area in section III is 1102 sites $/ \mathrm{cm}^{2}$, and in the black area is 169 sites $/ \mathrm{cm}^{2}$ at $\Delta T_{\text {sat }}=23.5 \mathrm{~K}$. As a result, it is confirmed that the NSD is not uniform and concentrated in the white area, while bubble formation in black oxide region is suppressed. According to these results, as the antirust effect decreases, the heating surface of the water jacket will be corroded and restrict the forced flow nucleate boiling.

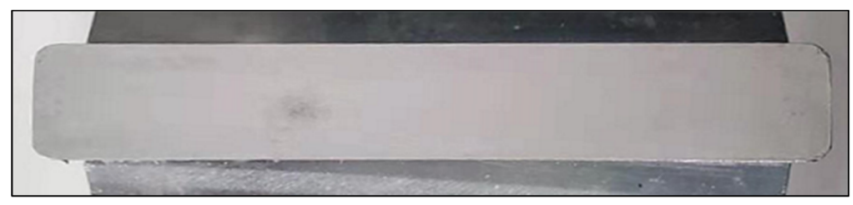

(a)

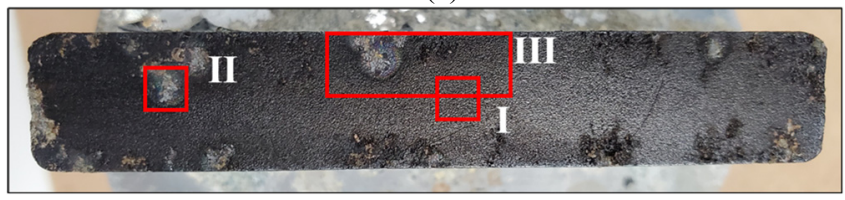

(b)

Fig. 3 Image of heating surface (a) before experiment and (b) after 70 hours heating experiment.

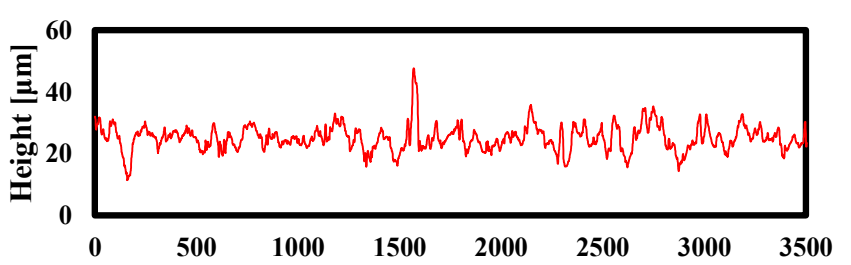

(a)

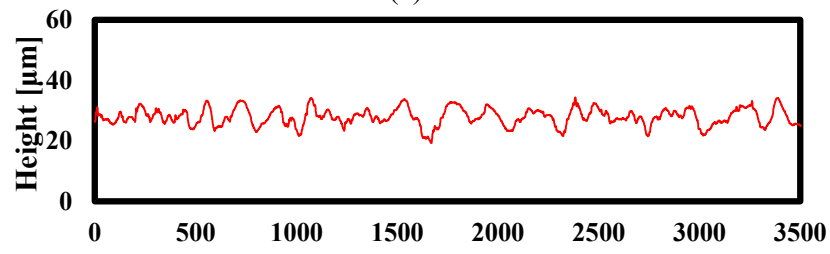

(b)

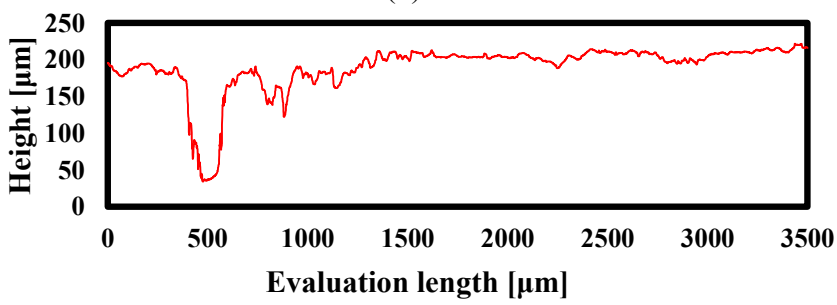

(c)

Fig. 4 Roughness curves of heating surface: (a) before the experiment, (b) at the black area I, (c) at white area II 
Vol.12, No.3(2021)

Table 2 Results of measured roughness parameters

\begin{tabular}{|c||c|c|c|}
\hline & $R_{l o}[\%]$ & $S_{a}[\mu \mathrm{m}]$ & $S_{s k}[-]$ \\
\hline \hline Base & 9.1 & 3.0 & 0.256 \\
\hline I & 1.9 & 2.3 & 0.009 \\
\hline II & 30.4 & 5.5 & -2.642 \\
\hline
\end{tabular}

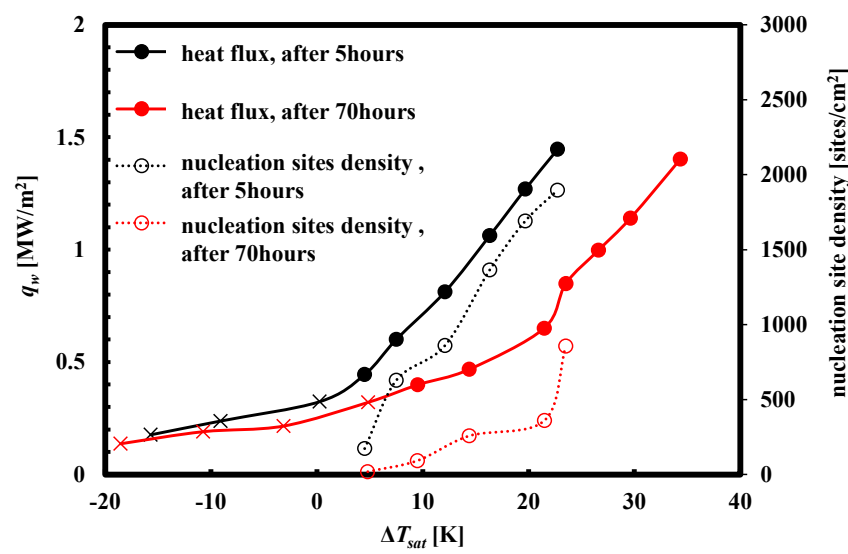

Fig. 5 Comparison of heat flux and NSD between the heating surface with and without corrosion

3.2. Comparison of water and EG50\% boiling phenomenon and heat flux

In our previous study ${ }^{(8)}$, the measurement of forced flow nucleate boiling heat flux on a corroded heating surface using water was presented. In this study, working fluid was chosen as EG50\%. The heat flux results using water and EG50\% under two different flow velocities are shown in Figure 6. According to the results, heat flux of both liquids increases with the increase of flow velocity. However, the heat flux of EG50\% was found to be smaller than water at each flow velocity. For this reason, bubble growth and departure phenomenon for both fluids are compared by images taken with a high-speed camera, shown in Figures 7 and 8 , respectively. For water, it was confirmed that the lift-off phenomenon from the heating surface occurred immediately as the bubbles were generated. For EG50\%, as shown in Figure 8, after the generation, bubbles did not depart, but slide along the heating surface, and the departure phenomenon was not confirmed in the observation field. Thus, the departure frequency of EG50\% bubbles was found to be significantly lower than water.

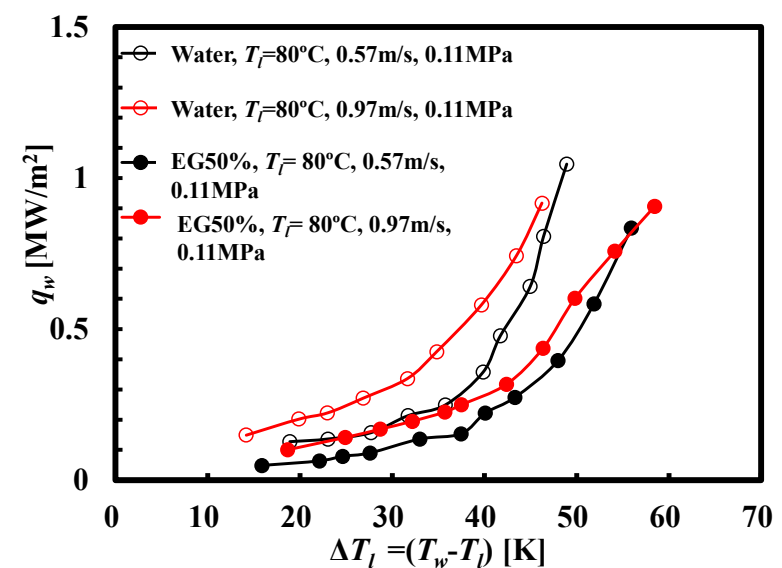

Fig. 6 Comparison of measured heat flux between using water and EG50\% as coolant.
The reason for the occurrence of bubble sliding phenomenon is related to the mole mass of ethylene glycol $\left(\mathrm{CH}_{2} \mathrm{OH}\right)_{2}, 62 \mathrm{~g} / \mathrm{mol}$, which is larger than that of water, $18 \mathrm{~g} / \mathrm{mol}$. Since ethylene glycol's molecular structure is more complex with more carbon and oxygen atoms, buoyancy force required to overcome gravity for EG50\% bubbles is found to be larger than water, which also meant that EG50\% departure radius was larger. As the radius of the bubble exceeds the superheat layer which is a part of temperature boundary layer near the superheated surface, the excess part will begin to condense. Furthermore, as the vaporization rate and condensation of the bubble reach equilibrium, the bubble will stop growing and move with the coolant flow. In the previous studies ${ }^{(11),(12)}$, it is considered that the nucleate boiling heat transfer is dominating the forced convection caused by bubble departure, thus weakening of this effect will lead to a decrease of nucleate boiling. As the other reason for the heat flux decreases, the differences in thermal properties can be considered as an additional reason for lower nucleate boiling heat flux values when EG50\% was used. Comparing with the thermal properties of water, thermal conductivity, specific heat, and latent heat of vaporization of EG50\% are lower, thus heat transfer is also lower. Moreover, since the viscosity of EG50\% is larger, which leads to a smaller Reynolds number under the same conditions, overall heat transfer decreases.

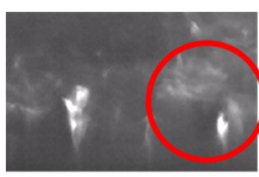

(a) $0 \mathrm{~ms}$

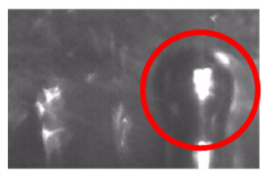

(d) $0.3 \mathrm{~ms}$

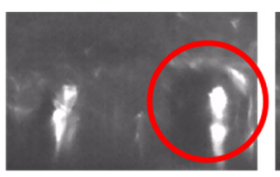

(b) $0.1 \mathrm{~ms}$

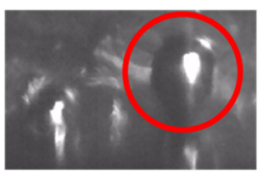

(e) $0.4 \mathrm{~ms}$

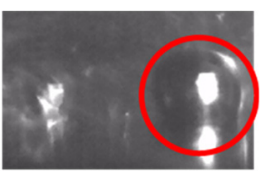

(c) $0.2 \mathrm{~ms}$

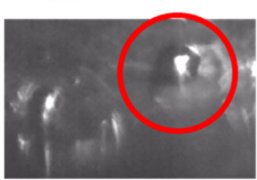

(f) $0.5 \mathrm{~ms}$
Fig. 7 Image of the water's bubble growth and departure

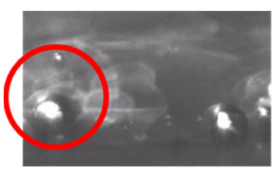

(a) $0 \mathrm{~ms}$

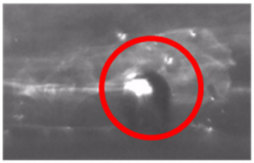

(d) $3 \mathrm{~ms}$

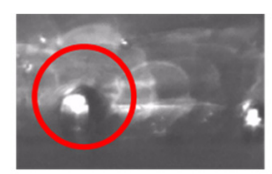

(b) $1 \mathrm{~ms}$

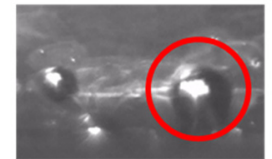

(e) $4 \mathrm{~ms}$

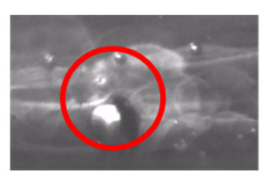

(c) $2 \mathrm{~ms}$

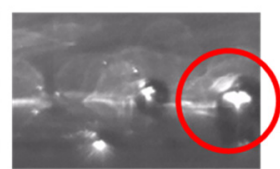

(f) $5 \mathrm{~ms}$
Fig. 8 Image of the EG50\%'s bubble growth and departure.

\subsection{Surface heat flux measurement using EG50\%}

The surface heat flux is measured on the corroded heating surface under the experimental conditions shown in Table 1. The measured heat flux results under different flow velocity, degree of subcooling and pressure conditions are given in Figures 9 (a), (b), and (c), respectively. Similarly, heat transfer coefficient results under the same conditions are given in Figures 10 (a), (b), and (c). Data without boiling are marked as " $\times$ ", and heat transfer 
coefficients from the transition state of convection and nucleate boiling heat transfer were not included in this paper.

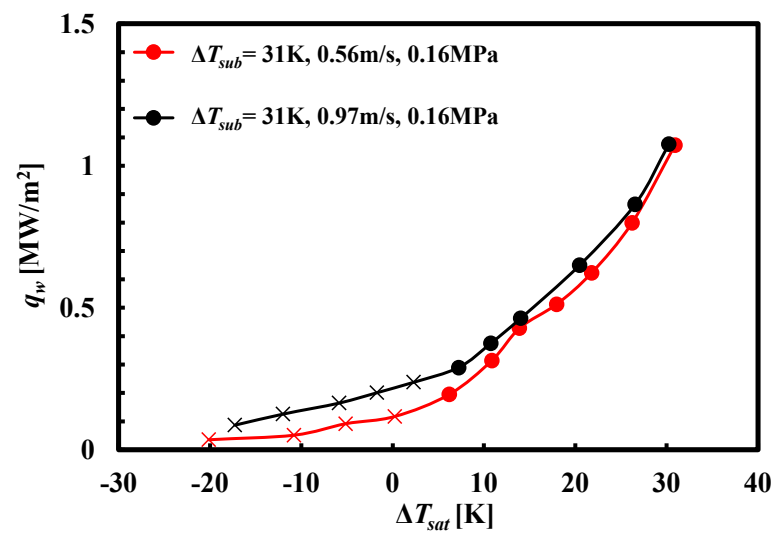

(a)

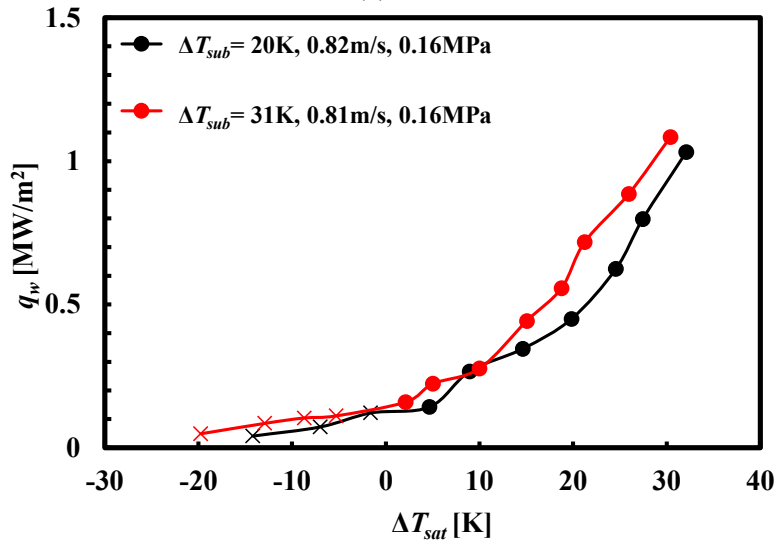

(b)

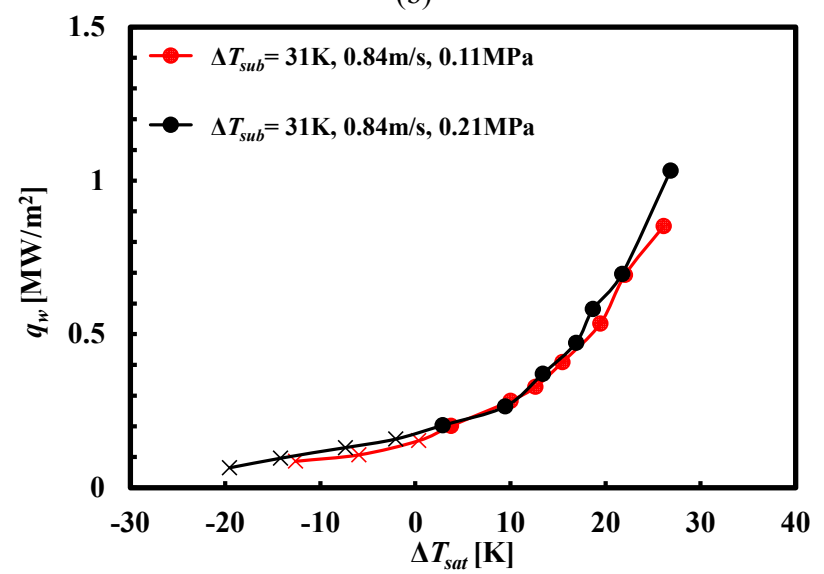

(c)

Fig. 9 Measured heat flux results under different (a) flow velocity, (b) degree of subcooling and (c) pressure conditions

According to these results, the effect of nucleate boiling on heat flux can be confirmed through the rapid increase rate of heat flux when $\Delta T_{\text {sat }}>0 \mathrm{~K}$. Comparing the measured results of heat flux from Figures 9 (a) to (c), the heat flux can be found to be larger when the flow velocity, degree of subcooling and pressure is larger. In Figure 10 (a) the results of the heat transfer coefficient with the increase of flow velocity from $0.56 \mathrm{~m} / \mathrm{s}$ to $0.97 \mathrm{~m} / \mathrm{s}$ are shown. The average heat transfer coefficient during the forced convection section increased by $3656.0 \mathrm{~W} / \mathrm{m}^{2}-\mathrm{K}$. However, as the nucleate boiling started, the heat transfer coefficient difference was 2101.2
$\mathrm{W} / \mathrm{m}^{2}-\mathrm{K}$. The results under the conditions of degree of subcooling of $20 \mathrm{~K}$ and $31 \mathrm{~K}$ are shown in Figure 10 (b). Heat transfer coefficient of forced convection without boiling stayed the same, while an increase of $6396.1 \mathrm{~W} / \mathrm{m}^{2}-\mathrm{K}$ was apparent of the subcooling after nucleate boiling started. Moreover, according to the pressure comparison results shown in Figure 10 (c), with the pressure rising from $0.11 \mathrm{MPa}$ to $0.21 \mathrm{MPa}$, the difference of heat transfer coefficient in the two fields of forced convection and nucleate boiling is not obvious.

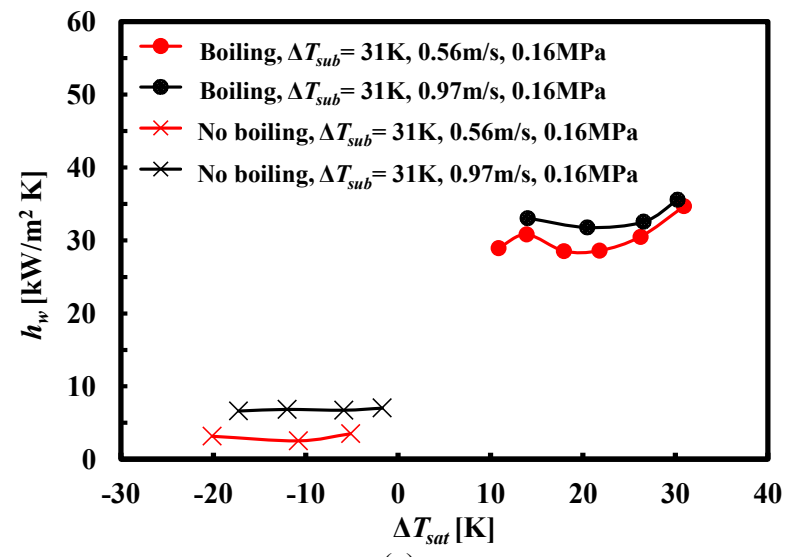

(a)

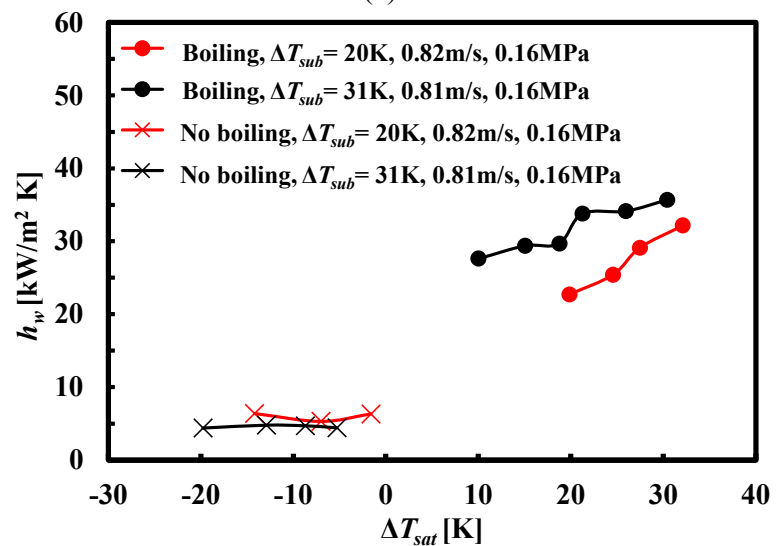

(b)

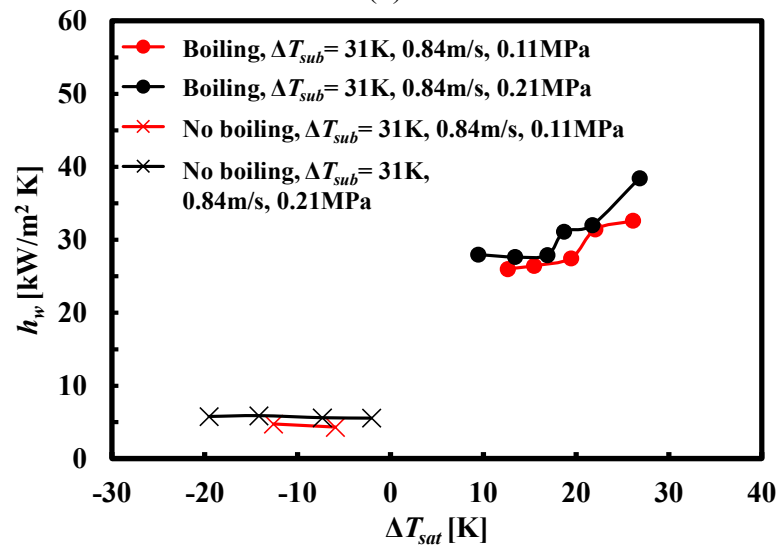

(c)

Fig. 10 Heat transfer coefficient results under different (a) flow velocity, (b) degree of subcooling and (c) pressure conditions

\subsection{Model construction}

A prediction model based on the experimental data using water and $\mathrm{EG} 50 \%$ as coolant is constructed to accurately predict the heat flux of forced convection nucleate boiling on the corroded 
Vol.12, No.3(2021)

heating surface. the superposition concept of chen's model (1) is used in this paper, which is written as:

$q_{w}=q_{l c}+q_{\text {boiling }}$

where the first term, $q_{l c}$, is the heat flux due to forced convection, and the second term, qboiling, is due to nucleate boiling. The first term according to the experimental data of water obtained in our previous study ${ }^{(8)}$, the Dittus-Boelter's model ${ }^{(12)}$ was revised to:

$q_{l c}=0.038 \operatorname{Re}^{0.8} \operatorname{Pr}^{0.4}\left(\lambda_{l} / d\right) \Delta T_{l}$

where $R e$ : liquid Reynolds Number [-], $P r$ : liquid Prandtl number $[-], \lambda_{l}:$ liquid conductivity $[\mathrm{W} / \mathrm{m}-\mathrm{K}], d:$ pipe's inner radius $[\mathrm{m}]$, $\Delta T_{l}$ : temperature difference between bulk temperature and surface temperature $[\mathrm{K}]$. Through the regression analyses, it was found that the product of Jakob number's, $J a$, power function and exponential function of $J a$ number has a good correlation which can be written as:

$q_{\text {boiling_Water }} \propto J a^{n} \exp (J a)$

where $q_{\text {boiling_Water }}$ is the nucleate boiling of water. $J a$ represents the ratio of sensible heat to latent heat. Since the boiling phenomenon of water and $\mathrm{EG} 50 \%$ was found to be different in this study, the boiling term of the nucleate boiling heat flux prediction model for water and EG50\% are constructed by dimensional analyses. In the process of dimensional analyses, according to the literature review (2), (3) and experimental results, the effective physical quantities for the nucleate boiling phenomenon are chosen as; constant volumespecific heat, degree of superheating, liquid density, viscosity coefficient, flow velocity, departure radius, acceleration of gravity, equivalence diameter of heated channel, surface tension, latent heat of vaporization, thermal conductivity, vapor density, degree of subcooling, pressure and heat transfer coefficient. In Forster \& Zuber's study ${ }^{(3)}$, the pressure term was used as the pressure difference between the vapor pressure and pressure at superheat temperature. However, in a subcooled nucleate boiling case, vapor pressure is difficult to predict preliminarily without experiments, thus the system pressure was used in our present study. There are 5 basic dimensions of the 15 mentioned variables including $L, M, T$, $\Theta, Q$, which are related to length, mass, time, temperature, and heat, respectively. According to the dimensionless Buckingham's $\pi$ theorem, the following dimensionless number groups were created:

$\pi_{1}=\frac{c_{p l} \mu_{l}}{\lambda_{l}} \pi_{2}=\frac{\rho_{v}}{\rho_{l}} \pi_{3}=\frac{\rho_{l}^{2} \sigma^{2} r_{L}^{2}}{\mu_{l}{ }^{2}} \pi_{4}=\frac{\rho_{l} \sigma L}{\mu_{l}{ }^{2}} \pi_{5}=\frac{c_{p l} \Delta T_{s a t}}{h_{l g}}$

$\pi_{6}=\frac{\mu_{l}^{2} P}{\sigma^{2} \rho_{l}} \pi_{7}=\frac{\mu_{l} u}{\sigma} \pi_{8}=\frac{\mu_{l}{ }^{4} g}{\rho_{l} \sigma^{2}} \pi_{9}=\frac{c_{p l} \Delta T_{s u b}}{h_{l g}} \pi_{10}=\frac{\mu_{l} h}{\rho_{l} c_{p l} \sigma}(4)$

Ten dimensionless number groups containing Prandtl number, $\mathrm{Pr}$, and Capillary number, $\mathrm{Ca}$, were created, which are shown in equations (5)-(8) related to the heat transfer coefficient are obtained by dimensional analyses. $\mathrm{Ca}$ expresses the relative effect of viscous drag forces versus surface tension forces acting across an interface between liquid and gas, and $\mathrm{Pr}$ is defined as the ratio of momentum diffusivity to thermal diffusivity. Then the dimensionless numbers $\pi_{2}, \pi_{5}, \pi_{3}$, and $\pi_{8}$ can be merged, and the dimensionless numbers are obtained as equation (6) and (7),

$\pi_{1}=\frac{c_{p l} \mu_{l}}{k_{l}}=P r_{l}$

$\frac{\pi_{5}}{\pi_{2}}=\frac{\rho_{l} c_{p l} \Delta T_{s a t}}{\rho_{v} h_{l g}}=J a$

$\pi_{3} \cdot \pi_{8}=\frac{r_{v}^{2} \Delta \rho g}{\sigma}=B o$

$\pi_{7}=\frac{\mu_{l} u}{\sigma}=C a$

where $B o$, Bond number, represents the ratio of buoyant force of the bubbles and surface tension. In this study, Fritz's Bo empirical equation (9) ${ }^{(13)}$ is used,

$B o=(0.0209 \beta)^{2}$

where $\theta$ is contact angle. Since the influence of wettability is not discussed in this paper, $B o$ is regarded as a constant. Thus, heat flux model for nucleate boiling, equation (1), can be re-written as:

$$
\begin{gathered}
q_{w}=q_{l c}+q_{\text {boiling }}=0.038 \operatorname{Re}^{0.8} \operatorname{Pr}^{0.4}\left(\lambda_{l} / d\right) \Delta T_{l} \\
+\gamma J a^{m} \exp (\beta J a) \operatorname{Pr}^{o} C^{p}\left(\frac{c_{p l} \Delta T_{s a t}}{h_{l g}}\right)^{s}\left(\frac{\rho_{l} c_{p l} P d_{c}}{\mu_{l}}\right) \Delta T_{s a t}
\end{gathered}
$$

where $c_{p l}$ : specific heat capacity $[\mathrm{J} / \mathrm{kg}-\mathrm{K}], \rho_{l}$ : liquid density $\left[\mathrm{kg} / \mathrm{m}^{3}\right], \Delta T_{\text {sub }}$ : degree of subcooling $[\mathrm{K}], \Delta T_{\text {sat }}$ : degree of superheating $[\mathrm{K}], h_{l g}$ : latent heat of vaporization $[\mathrm{J} / \mathrm{kg}], \mu_{l}:$ liquid viscosity $[\mathrm{Pa}-\mathrm{s}], d_{c}$ : equivalence diameter of heated channel $[\mathrm{m}]$. To find the optimal solution of the undetermined coefficient, $\gamma, \beta$, and exponents, $m, o, p, s$ of $q_{\text {boiling }}$ were calculated from the Least Mean Square (LMS) method by using experimental heat flux data of water and EG50\%. As a result, the equations of water and EG50\% to predict the forced flow nucleate boiling heat flux are proposed as follows:

$$
\begin{aligned}
& q_{w_{-} \text {Water }}=q_{l c}+q_{\text {boiling }} \text {-Water } \\
& =0.038 \operatorname{Re}^{0.8} \operatorname{Pr}^{0.4}\left(\lambda_{l} / d\right) \Delta T_{l}+3.24 \times 10^{-7} \mathrm{Ja}^{1.5} \\
& \exp (0.19 \mathrm{Ja}) \operatorname{Pr}^{-2.5} \mathrm{Ca}^{0.11}\left(\frac{c_{p l} \Delta T_{\text {sub }}}{h_{l g}}\right)^{0.59}\left(\frac{\rho_{l} c_{p l} P d_{c}}{\mu_{l}}\right) \Delta T_{\text {sat }}
\end{aligned}
$$

$q_{w_{-} E G}=q_{l c}+q_{\text {boiling_EG }}$

$$
\begin{gathered}
=0.038 \operatorname{Re}^{0.8} \operatorname{Pr}^{0.4}\left(\lambda_{l} / d\right) \Delta T_{l}+8.01 \times 10^{-6} J^{1.28} \\
\operatorname{Pr}^{0.78} \mathrm{Ca}^{-0.28}\left(\frac{c_{p l} \Delta T_{s u b}}{h_{l g}}\right)^{0.49}\left(\frac{\rho_{l} c_{p l} P d_{c}}{\mu_{l}}\right) \Delta T_{\text {sat }}
\end{gathered}
$$

where $q_{\text {boiling_EG }}$ is the nucleate boiling heat flux of EG50\%. Since the result of coefficient $\beta$ is obtained as 0 , in equation (12), it is proved that the heat flux of EG50\% exponential function term of $\mathrm{Ja}$ is uncorrelated. Furthermore, the exponents of $\mathrm{Pr}$ and $\mathrm{Ca}$ in these models are shown a different tendency. Since the viscosity of EG50\% is larger than water (the viscosity at $100{ }^{\circ} \mathrm{C}$, water: 0.00282 Pa-s, EG50\%: $0.0007 \mathrm{~Pa}-\mathrm{s})$, the addition of EG increases increased viscosity of the coolant. In the calculation of $\mathrm{Pr}$ and $\mathrm{Ca}$, both viscosity terms are on the numerator, so the $\mathrm{Pr}^{\circ}$ term and $\mathrm{Ca}^{p}$ term of equation (10) should have larger values in the EG50\% case. In 
our calculation, the value of $\operatorname{Pr} 0.78$ in $q_{w_{-} E G}, 3.8$, is larger than $\operatorname{Pr}$ 2.5 in $q_{w_{-} w a t e r}, 0.36$, and the value of $\mathrm{Ca}^{-0.28}$ in $q_{w_{-} E G}, 4.09$, is larger than $\mathrm{Ca}^{0.11}, 0.52$ in qw_water. According to these results, it is confirmed that the values of the $P r^{\circ}$ term and $C a^{p}$ term changed with the same tendency with EG concentration ratio increase, and the effects of the EG concentration ratio on nucleate boiling heat transfer is planned to be investigated in our future work.

In order to verify the calculation accuracy of the $q_{w_{-} \text {Water }}$ and $q_{w_{-} E G}$, the predicted values from the models were compared with the experimental data as shown in Figures 11 and 12, where $q_{\exp }$ is the heat fluxes measured using water or EG50\% and $q_{\text {model }}$ is the heat fluxes predicted by three different models. According to the results, $q_{w_{-} \text {Water }}$ and $q_{w_{-} E G}$ data points can be seen to be well concentrated on the dotted line. The average relative error of $q_{w_{-} \text {Water }}$ is found to be $9.9 \%$ and the relative error of $q_{w_{-} E G}$ is calculated as $10.1 \%$. Moreover, the prediction accuracy of Chen's and Steiner et al.'s models are compared with the experimental results, as shown in Figures 13 and 14. Average relative errors of each model are shown in Table 3, where $q_{w_{-}}$Chen is the predicted heat fluxes by using Chen's model ${ }^{(1)}$ and $q_{w_{-} \text {Steiner }}$ is the predicted heat fluxes by using Steiner et al.'s model ${ }^{(2)}$. It is confirmed that the predicted values from both models on the corroded heating surface are smaller than the experimental values. Especially for the prediction results of water, in the region of high heat flux values, the relative errors tend to increase further. Regarding the results shown in Table 3, it can be confirmed that for both water and EG50\% cases, newly proposed model showed better accuracy.

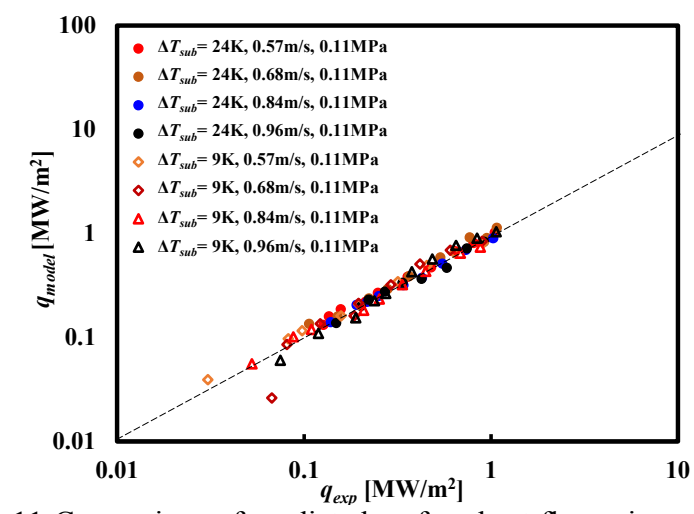

Fig. 11 Comparison of predicted surface heat flux using equation (11) with experimental surface heat fluxes of water

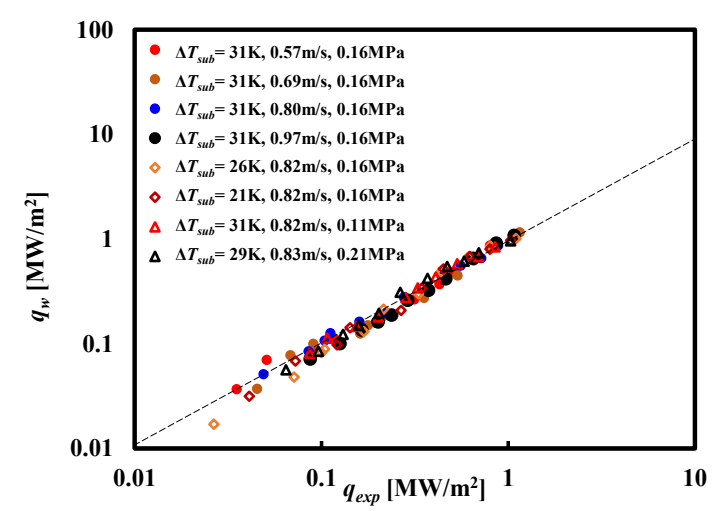

Fig. 12 Comparison of predicted surface heat flux using equation (12) with experimental surface heat flux of EG50\%

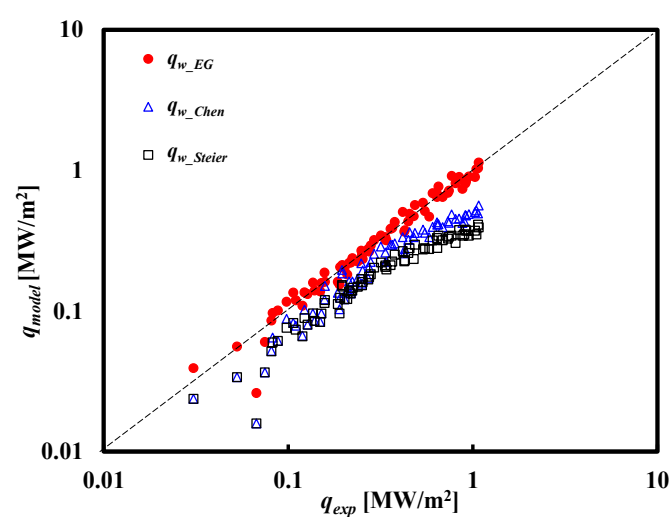

Fig. 13 Comparison of correlation of equation (11), Chen's and Steiner et al.'s models when water was used as a coolant

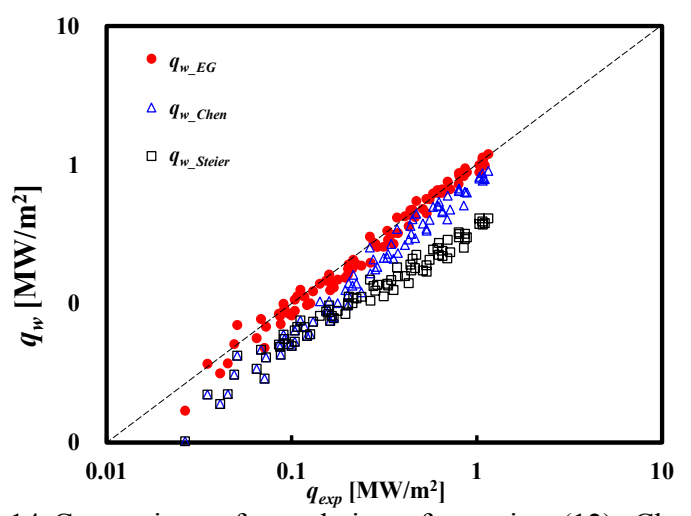

Fig. 14 Comparison of correlation of equation (12), Chen's and Steiner et al.'s models when EG50\% was used as coolant

Table 3 Comparison of average relative errors from equation (11), equation (12), Chen's model and Steiner et al.'s model at each present experimental condition.

\begin{tabular}{|c||c|c|c|c|}
\hline & $q_{w_{-} \text {water }}$ & $q_{w_{-} E G}$ & $q_{w_{-} \text {Chen }}$ & $q_{w_{-} \text {Steiner }}$ \\
\hline \hline Water & $9.9 \%$ & & $32.8 \%$ & $42.5 \%$ \\
\hline EG50\% & & $10.1 \%$ & $33.8 \%$ & $53.9 \%$ \\
\hline
\end{tabular}

\section{Conclusions}

For improving the prediction accuracy of forced flow nucleate boiling heat transfer model, the heat fluxes were measured using water and $\mathrm{EG} 50 \%$ as coolant fluids, which leads to corrosion on the heating surfaces. The heat fluxes of the heating surface were measured at different degrees of subcooling temperatures, flow velocities and pressure. The nucleate boiling phenomenon and the heat fluxes for water were compared with those for EG50\%. Subsequently, ten different dimensionless groups were created by dimensional analyses to develop new empirical models for water and EG50\% usage. The important conclusions obtained from this study are summarized below:

(1) After the heat flux measurement experiment using EG50\%, most of the area on the heating surface was covered with black oxide and multiple local pore corrosion areas were found. Moreover, the decrease of the number and depth of tiny cavities in the black corrosion area were measured by a laser microscope. By comparing the results of heat flux measurement before and after the corrosion, the NSD and surface heat flux on the corroded heating surface is decreased. 
(2) As a result of the bubble sliding phenomenon of EG50\% and thermal property differences between water and EG50\%, the forced flow nucleate boiling heat flux of EG50\% was found to be lower than water.

(3) By comparing the nucleate boiling heat flux of EG50\% under the flow velocity, degree of subcooling and pressure change conditions, it was confirmed that the nucleate boiling heat transfer coefficient will be greatly promoted with the increase of the degree of subcooling.

(4) The heat flux prediction models for water and EG50\% usage on corroded heating surfaces were constructed by dimensionless numbers, $\mathrm{Ja}, \mathrm{Pr}$, and $\mathrm{Ca}$ obtained by the dimensional analyses. The average relative error is evaluated to be $9.7 \%$ and $10.4 \%$, for water and $\mathrm{EG} 50 \%$ usage, respectively.

\section{Acknowledgments}

This work was the result of a collaborative research program with the Research association of Automotive Internal Combustion Engines (AICE) for fiscal year 2019 - 2020. The authors gratefully acknowledge the concerned personnel.

\section{References}

(1) J.C. Chen, A correlation for boiling heat transfer to saturated fluids in convective flow, ASME preprint 63 HT34 presented at the 6th National Heat Transfer Conference, Boston, (1963).

(2) H. Steiner, A. Kobor and L. Gebhard, A wall heat flux model for subcooled boiling flow, International Journal of Heat and Mass Transfer, Vol. 48, No. 19-20, pp. 4161-4173, (2005).

(3) H.K. Forster and N. Zuber, Dynamics of vapor bubbles and boiling heat transfer, AIChE Journal, Vol. 1, No. 4, pp. 531535, (1955).

(4) A.J. Torregrosa, A. Broatch, P. Olmeda and O. Conejo, Experiments on subcooled flow boiling in I.C. engine-like conditions at low flow velocities, Experimental Thermal and Fluid Science, Vol. 52, pp. 347-354, (2014).

(5) M. Gollin, D. Bjork, Comparative performance of ethylene glycol/water and propylene glycol/water coolants in automobile radiators, SAE Tech. Papers, No. 960372, (1996).

(6) M. Bialy, K. Pietrykowski, T. Tulwin, P. Magryta, CFD numerical simulation of the indirect cooling system of an internal combustion engine, Combustion Engines, Vol. 170, No. 3, pp. 8-18, (2017).

(7) R. Cipollone, M. Borasso, D. DiBattista, M. Benincasa, A dynamic test bench for the cooling water pump characterization under real operating conditions, SAE Tech. Papers, No. 2018-37-0024, (2018).

(8) H. Chen, E. Yilmaz, K. Asano, R. Shindo, A. Homma, N. Kimata, T. Suzuki, M. Ichiyanagi, Effects of coolant flow characteristics and channel surface temperature on nucleate boiling heat transfer in IC engine cooling system, International Journal of Automotive Engineering, Vol. 11, No. 4, pp. 143-150, (2020).

(9) H. Yamada and T. Okamoto, Effect of water purity on the formation and the corrosion resistance of boehmite films -
Studies on boehmite forming process (2nd report)-, Journal of Japan Institute of Light Metals, Vol. 21, No. 6, pp. 405-412, (1971).

(10) H. Steiner, B. Breitschädel, G. Brenn, H. Petutschnig, C. Samhaber, Nucleate boiling flow - experimental investigations and wall heat flux modelling for automotive engine applications, WIT Trans. on Engineering Sciences, Vol. 61, pp. 169-178, (2008).

(11) W.M. Rohsenow, Heat transfer with evaporation, Heat Transfer - A Symposium held at the University of Michigan During the Summer of 1952, Univ. of Michigan Press, pp. 101-150, (1953).

(12) F. W. Dittus and L. M. K. Boelter, Heat transfer in automobile radiators of the tubular type, Univ. of California. Publications in Eng., Vol.2, No.13, pp.443-461, (1930).

(13) W. Fritz : Berechnung des Maxima Volumens von Dampfblassen, Physik. Zeitschr, Vol. 36, pp. 397-388, (1935). 